\title{
Exploring an Automated Feedback Program 'Grammarly' and Teacher Corrective Feedback in EFL Writing Assessment: Modern vs. Traditional Assessment
}

\author{
M. Ali Ghufron \\ English Education Department of IKIP PGRI Bojonegoro, Jl. Panglima Polim 46 \\ Bojonegoro, East Java, Indonesia
}

\{ali.ghufron@ikippgribojonegoro.ac.id\}

\begin{abstract}
This study aimed at (1) exploring the teachers and students' perceptions and attitudes toward the implementation of 'Grammarly' and teacher corrective feedback, (2) uncovering the strengths and weaknesses of the use of 'Grammarly' and teacher corrective feedback in EFL writing class. This study employs a case study design. The findings of this study show the positive perceptions and attitudes of teachers and students on the implementation of both 'Grammarly' and teacher corrective feedback. 'Grammarly' is better in reducing errors in terms of vocabulary usages (diction), language use (grammar), and mechanics of writing (spelling and punctuation). However, it is less effective to improve the content and organization of students' EFL writing. On the contrary, teacher corrective feedback is better in terms of improving the content, organization, and mechanics of writing, but it is less effective in terms of language use and diction.
\end{abstract}

Keywords: Grammarly, teacher corrective feedback, modern assessment, traditional assessment, automated feedback program

\section{INTRODUCTION}

As a global effect and one of the challenges in this digital age, EFL teachers have to integrate technology in the EFL classrooms. Dealing with EFL writing, teachers have made some efforts to improve the students' skill in EFL writing. Various learning methods have been implemented including teacher corrective feedback and automated feedback by using certain computer tools [1]-[5]. The use of Internet in teaching and leraning process can encourage students to be independent learners for their own study and can enable teachers as facilitators in the process of learning [6]. Lecturers/teachers, in this digital age, are aware of some automated feedback programs to assist them in teaching and learning, such as wiki, Facebook, Ms. Word computer software, Grammar software, etc. [7]-[11].

'Grammarly' is one of the automated feedback programs that can be implemented in the EFL writing class. It is an online website for proofreading that can be used for identifying grammatical errors of documents. It offers correction for spelling, punctuation, synonyms, and detection of plagiarism [12]. 'Grammarly' helps students and teachers to correct EFL writing. 
It is because' 'Grammarly' is not only capable of identifying punctuation and spelling errors, but also the correcting noun and providing several alternatives for the misspelled words, identifying fragments and offering verb form [2].

In many research types, including the EFL writing class, the researchers found the use of automated feedback program in teaching and learning. Many articles of different lengths and depths in the use of automated feedback program are also exist, such as using FB for EFL, the use of automated feedback program such as 'Grammarly', Ginger, and Ms. Word, etc. Those articles discuss the effectiveness, benefits, and disadvantages of using automated feedback program, the reasons why automated feedback program should be used in teaching and learning processes, and so on [2], [3], [13]-[17]. All articles above suggest the use of certain automated feedback program, particularly in the context of higher education, since it has great potential for EFL learning.

I, therefore, agree with [2] that the tools and platforms for grammar checker, such as Grammarly and Ginger can help us to be a better writer, and become a new site for research [2], [3], [18]. However, only a few research studies focus on the use of grammar checker. The use of 'Grammarly' in helping students to reduce EFL writing errors has been revealed by [3]. The students' mistakes are identified and alternative answers are provided. The term automated feedback grammar is a term used in various forms of teaching writing [19].

Another common method, used for many years, is teacher corrective feedback to correct student errors in EFL writing. Corrective feedback (CF) is an inevitable teaching strategy implemented by teachers in the EFL classroom, especially EFL writing. It can be used to highlight errors in writing tasks for EFL, i.e. grammatical errors, spelling errors, diction errors, etc. [20]. Teachers use corrective feedback to inductively educate students, criticize and comment on the work of students. Corrective feedback has become a necessity for all teachers and students and has been done for centuries in their exercises, test papers, or throughout their course [1].

Several studies have shown that corrective feedback is efficient; however, a number of problems appear to result in failure. Students are still struggling to deal with and learn from the corrective feedback themselves. In the absence of sufficient linguistic knowledge to make it easier for all of them to handle the complex linguistic errors themselves, they cannot cope with their errors [1], [21].

Several kinds of corrective feedback are available. Indirect corrective feedback is among these. The errors made by the students are indirectly corrected by the teacher by giving indications [22]. The indications are given in various ways, such as highlighting, underlining, circling, or coding. Following the indirect feedback from the teacher, the students are independently correct reformulate their mistakes. The ability of students to correct their mistakes by themselves is called self-correction [23]. Self-reformulation is where students themselves rephrase the correct version of the phrases with a mistake. This, therefore, generates cognitive beliefs and promotes learning among students [24].

Feedback can improve students' self-confidence so they can do their best to achieve success. Teacher feedback is the verbal reaction of the teacher to grammatical mistakes made by the students during the teaching process [25]. Some studies show how corrective feedback and self-correction impede the improvement of students' writing skill in EFL. [26], for example, showed indirect feedback is more efficient than direct feedback for the correction of spelling errors. Indirect corrective feedback had a positive impact on the accuracy of grammar structures used by students [27]. Also, confirmed by [28], that indirect corrective feedback improves writing accuracy compared with direct corrective feedback. Indirect corrective feedbacks were also found to be effective because they enable students to have a deeper 
language processing, which enhances grammar accuracy compared to direct corrective feedback. While [29] has found that the indirect feedback group is better in terms of post-test delays than the direct corrective feedback group.

\section{METHODOLOGY}

\section{a. Research Design and Research Participants}

This study employs a case study design. A case study is used in many situations to contribute to our knowledge of individual, group, organizational, social, political, and related phenomena [30]. This study was conducted in English Education Department, Faculty of Languages and Arts Education, IKIP PGRI Bojonegoro, East Java, Indonesia, at the even semester in the academic year of 2017/2018. There were 2 EFL writing teachers and 120 from the first-and-second grade students of English Education Department. The participants in this study were chosen by using two types of purposeful sampling technique i.e. criterion and intensity sampling, in order to purposefully selects participants to maximize information [31].

\section{b. Data Collection Technique}

Close-ended Questionnaires and Interviews

Close-ended questionnaire was used to reveal the teachers and students' perceptions and attitudes toward the implementation of 'Grammarly' and teacher corrective feedback and the strengths and weaknesses of the use of 'Grammarly' and teacher corrective feedback during EFL writing class. Close-ended interview was also conducted with the teachers and some students who were chosen purposively.

Open-ended Interviews

Open-ended interview was also conducted with the teachers and some students who were chosen purposively. The responses from interview sessions were transcribed for analysis by using the coding processes.

\section{c. Data Analysis}

After the data was gotten, then, it was analyzed by examining the "bottom-up" approach to analysis. The researcher first collect data and then prepare it for data analysis. This analysis initially consists of developing a general sense of the data, and then coding description and themes about the central phenomenon [32]. In this study, coding schemes were used to gain a more detailed perspective about what was occurring based on the purpose of the study. These coding schemes helped to analyze the transcripts of the participants. Besides, descriptive statistics were also used to analyze quantitative data gained from the questionnaires.

\section{FINDINGS AND DISCUSSION}

The Teachers and Students' Perceptions and Attitudes toward the Implementation of 'Grammarly' and Teacher Corrective Feedback

From the close-ended questionnaire distributed to 120 students and 2 EFL writing teachers and followed by close-ended interview to 20 students and 2 EFL writing teachers, it was revealed that the majority of the students, about $97 \%$, agreed that both 'Grammarly' and teacher corrective feedback could directly and indirecty improve students' EFL writing. Besides, they also could motivate the students to always keep writing in English. From the 
queationnaire, it was also revealed that $98 \%$ of the students responded positively to the implementation of both 'Grammarly' and teacher corrective feedback. Meanwhile, the results of the questionnaire distributed the 2 EFL writing teachers and also close-ended interview, the instruments disclosed that the teachers asserted that the students looked motivated during EFL writing class when both 'Grammarly' and teacher corrective feedback are implemented. The teachers also agreed that the students' EFL writing are improved. Further, the teachers admitted that the students showed their positive responses during EFL writing class.

Further, from open-ended interview, it was found that the students have a positive perception toward the implementation of both 'Grammarly' and teacher corrective feedback. By using 'Grammarly' the students could independently check their own writing and assess it. They could immediately check their grammatical structures, mechanics, spelling, and of course, the organization and content of their writing. This activity really challenges them and makes them more motivated. Meanwhile, when the teacher corrective feedack is implemented, they also really curious with the teacher's feedback given through some notes. Sometimes, the teacher also inserted a motivation to motive the students. This makes the students feel courages and motivated to keep learning and writing in English. The following is the inteview excerpt.

"Well, I think both the automated feedback program, in this case is 'Grammarly', and teacher corrective feedback are two different technique of assessment. The first is a modern teachnique of EFL writing assessment, and the latter is the traditional one. However, both have great impact on our EFL writing skill. Both could improve our EFL writing and I, personally, really love those technique. If I use 'Grammarly' I was challenged to work and assess my writing independently. I could directly check my grammar, mechanics, spelling, content, and sentence organization by myself. This really makes me motivated and feel that ...emmm.. 'wow', I did it, haha.. (laughing). And if the teacher corrective feedback is implemented, I also that the teacher's comments and feedbacks, usually in the form notes, make me courages and I think that the corrections are from realiable source, from the teacher himself. And sometimes, the teacher also inserted some motivations to make us more motivated to alsways keep learning and writing" (AM)

In addition, the results of open-ended interview to the EFL writing teachers also disclose that during the teaching and learning process of EFL writing, the students were more motivated, show their passion in writing, and there is a significant improvement in their EFL writing. This happened when both 'Grammarly' and teacher corrective feedback are implemented in EFL writing class. The following is the interview excerpt.

"Hmm... yeah, the students always showed their positive attitudes and responses during the imlementation of both 'Grammarly' and teacher corrective feedback. When the students were asked to assess their own writing using 'Grammarly', they were couraged and can do it independently. They were enthusiatics to do self-evaluation using the automated feedback program. Therefore, they writing is improved significantly. Then, when I implemented traditional technique of assessment, in this case is teacher corective feedback, they were curious to see the results of my evaluation. They always revise their writing based on my comments and suggestions. And in fact, this technique is also effective to improve their EFL writing. Overall, the students showed their positive attitutes and perceptions in both technique of assessment." (FND) 
These results are supported by [33]. They state that both written feedback, such as teacher corrective feedback, and computer-mediated feedback, such as 'Grammarly', are crucial for encouraging and consolidating learning in terms of EFL/ESL writing. They are essential for developing ESL/EFL writing skills, both for their potential for learning and for students' motivation. Corrective feedback is an inevitable teaching strategy in an ESL/EFL classroom, especially ESL/EFL writing [1]. Furthermore, e-feedback, such as 'Grammarly', could develop learners' writing accuracy and attitudes toward CALL (Computer Assisted Language Learning) [34].

The Strengths and Weaknesses of the Use of 'Grammarly' and Teacher Corrective Feedback during EFL Writing Class

From the results of the close-ended questionnaire given to the teacher, it is revealed that 'Grammarly' is better in reducing errors in terms of vocabulary usages (diction), language use (grammar), and mechanics of writing (spelling and punctuation). However, it is less effective to improve the content and organization of students' EFL writing. On the contrary, teacher corrective feedback is better in terms of improving the content, organization, and mechanics of writing, but it is less effective in terms of language use and diction. Those results were also supported by the findings of the questionnaire distributed to 120 students. The results are presented in Figure 1 and 2 in the followings.

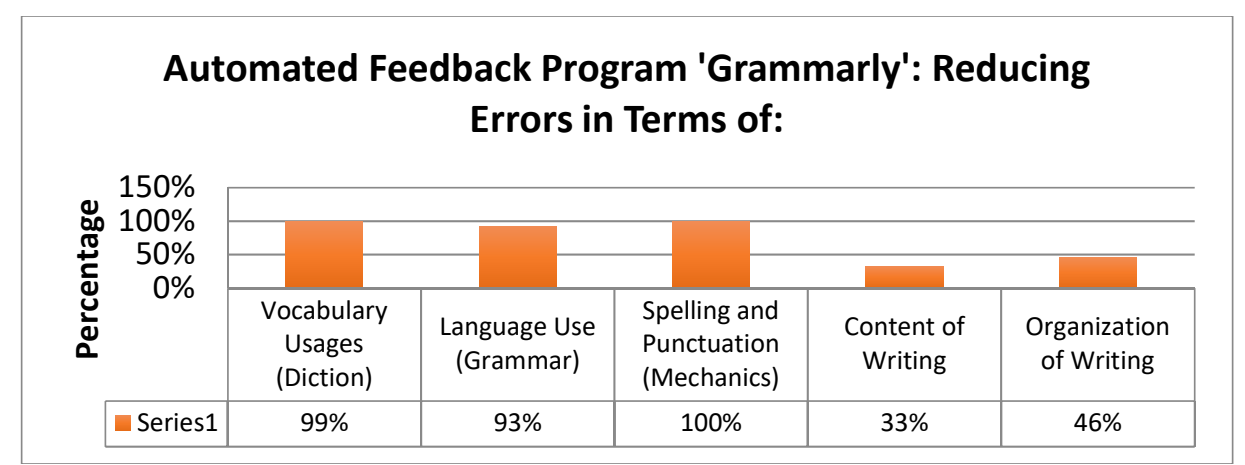

Fig. 1. The Results of the Questionnaire Distributed to Students Dealing with 'Grammarly'

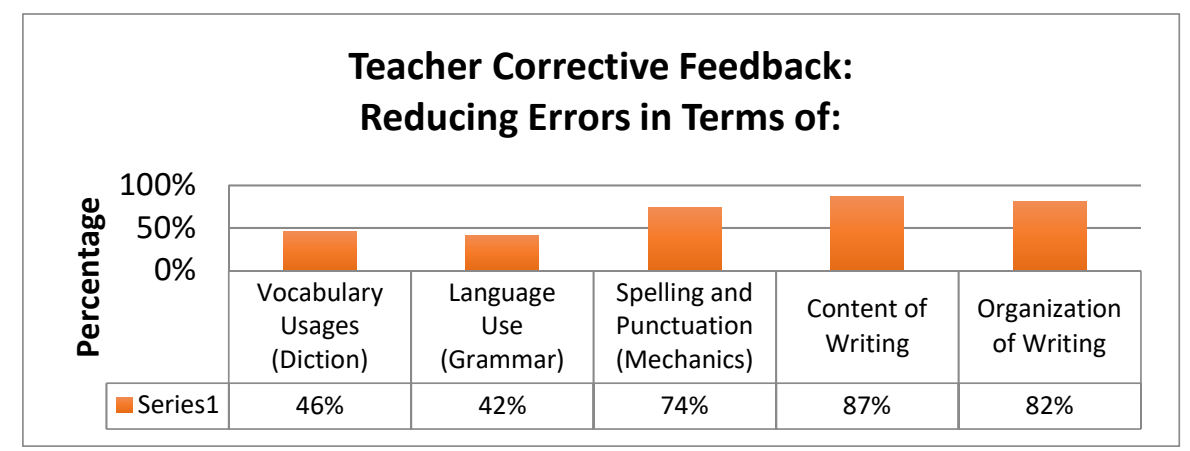

Fig. 2. The Results of the Questionnaire Distributed to Students Dealing with Teacher Corrective Feedback 
In addition, the results of the close-ended interview were in line with the results of questionnaire distribution. 'Grammarly' is better in reducing errors in terms of vocabulary usages (diction), language use (grammar), and mechanics of writing (spelling and punctuation). However, it is less effective to improve the content and organization of students' EFL writing. On the contrary, teacher corrective feedback is better in terms of improving the content, organization, and mechanics of writing, but it is less effective in terms of language use and diction.

Further, from the open-ended interview, it was revealed that 'Grammarly' is better in reducing errors in terms of vocabulary usages (diction), language use (grammar), and mechanics of writing (spelling and punctuation). However, it is less effective to improve the content and organization of students' EFL writing. One of the students answered that this is because "Grammaly' can identify EFL writing mistakes and/or errors in terms of vocabulary usages, language use, and mechanics clearly and directly. Grammarly is also able to identify the missing spaces after the periods and the spelling mistakes, including the proper noun and provided several alternative possibilities (feedback provision) for the misspelled words. During the implementation of 'Grammarly' program, the students were asked to independently evaluate their own writing. This encourages them to get engaged deeply in teaching and learning process. These also make them more motivated and have positive attitudes towards the use of online learning system. The following is the interview excerpt.

'Yeah, I think when I use 'Grammarly', it is easily for us to detect the errors in terms of spelling and punctuation, grammar, and diction. The program automatically detects and identifies it. It is no wonder if the students will get used to identifiy the same things as 'Grammarly' does during their writing, therefore, their writing is continuously improving. On the contrary, 'Grammarly' could not identify the sentence organization accurately and also the content of writing as well. So, for the rest two indicators of writing, it is less effective. However, the thing that makes us more motivated and courages is indenpendent evaluation of our writing". (SM)

On the contrary, teacher corrective feedback is better in terms of improving the content, organization, and mechanics of writing, but it is less effective in terms of language use and diction. One of the teachers said that it is because the students whose works evaluated by teacher corrective feedback tend to have better content, organization, and also mechanics. This is because teacher corrective feedback, usually, pays more attention to those aspects. It is because the corrector is the teacher him/herself. The teacher will easily recognize if there is a gap between the topic and the content. The teacher also can feel sensitively if he/she finds that the paragraph has bad movement and bad coherence and some mistakes in spelling and punctuations. If it is so, the teacher, then, highlights those parts and gives comments by writing some notes on students' paper. The students who understand the feedback given by the teacher will try to revise their works based on the suggestion.

"Well, I think when the students' works are evaluated through teacher corrective feedback, the teacher's attention is focusing more on content, organization, and mechanics, then followed by diction and grammar. The first three indicators are easily identified by the teacher, that is why teacher usually focus on those aspects. Meanwhile, for the rest two indicators, teachers needs to read the students' writing deeply and some teachers ignore that. Therefore, it is no wonder if the students writing is significantly improved in terms of content, organization, and mechanics". (FND)

'Grammarly' is one of automated feedback programs that can be used in language learning, especially in assessing EFL writing, and can give good contribution to the 
improvement of language skills [2]. It also can identify fragments and offer advice on verb form. The feedback provision in 'Grammarly' also gives positive contribution that makes the students easily recognize their mistakes and improve their writing [3]. Further, [1] argue that teacher corrective feedback (indirect corrective feedback) is important to be implemented in EFL writing class as it encourages students to find their weaknesses, understand their weaknesses and find a solution to their weaknesses. Through teacher corrective feedback, the students will learn a process of personal knowledge discovery of what they know and what they do not know. They will also able to bridge the gap by finding the correct answer. The students will internalize what they have learned through experience of finding the correct answer.

\section{CONCLUSIONS}

To sum up the findings and discussion above, it can be inferred that this study show the positive perceptions and attitudes of teachers and students on the implementation of both 'Grammarly' and teacher corrective feedback. 'Grammarly' is better in reducing errors in terms of vocabulary usages (diction), language use (grammar), and mechanics of writing (spelling and punctuation). However, it is less effective to improve the content and organization of students' EFL writing. On the contrary, teacher corrective feedback is better in terms of improving the content, organization, and mechanics of writing, but it is less effective in terms of language use and diction. This study comes to the conclusion that technology, as a part of modern assessment, could not fully support the process of EFL assessment. It still needs some traditional ways of assessment such as teacher corrective feedback in order to get more comprehensive results of EFL writing assessment.

This study has also discovered the negative results. Some of the students did not use the automated feedback program precisely enough. Some of the students are still confused with the system's feedback. They could therefore not perfectly correct their works themselves. This is especially the case with long sentences of grammatical feedback. It is because they still have poor language skills and thus are confused with the options. Students with low language skills may not be able to deal with the process of interlanguage correctness as their English language know-how is limited to help them find the correct response [21]. This shows that not all automated feedback programs are reliable enough to be mentioned. Some websites could not provide users with the right answers without adequate knowledge and information.

The teachers are also encouraged to rely not only on the automated feedback program as all writing indicators are not fully assessed, but also the teacher's work is evaluated through corrective feedback. Corrective feedback from the teacher can be used to monitor the content and organization of the EFL writing of students.

\section{References}

[1] A. N. Dodgson, B. Tariq, M. Alauyah, and M. Yusof, "The Secondary School Students' Usage of English Learning Websites to Self-Correct Writing Errors," Asian Tefl, vol. 1, no. 11, pp. 2503-2569, 2016.

[2] P. Daniels and D. Leslie, “@ CUE Grammar Software Ready for EFL Writers ?,” pp. 391-401, 2013.

[3] A. Qassemzadeh and H. Soleimani, "The Impact of Feedback Provision by Grammarly Software and Teachers on Learning Passive Structures by Iranian EFL Learners," Theory Pract. Lang. Stud., vol. 6, no. 9, p. 1884, 2016.

[4] K. Jafarian, A. Soori, and R. Kafipour, "The Effect of Computer Assisted Language 
Learning (CALL) on EFL High School Students' Writing Achievement," Eur. J. Soc. Sci., vol. 27, no. 2, pp. 138-148, 2012.

[5] M. Godwin, "International Students Use of Technology for Improving Writing Skills in College," 2016.

[6] M. K. Kabilan and B. M. Rajab, "The utilisation of the Internet by Palestinian English language teachers focusing on uses, practices and barriers and overall contribution to professional development.," Int. J. Educ. Dev. using Inf. Commun. Technol., vol. 6, no. 3, pp. 56-72, 2010.

[7] M. K. Kabilan, N. Ahmad, and M. J. Z. Abidin, "Facebook: An online environment for learning of English in institutions of higher education?," Internet High. Educ., vol. 13, no. 4, pp. 179-187, 2010.

[8] Melor Md Yunus and H. Salehi, "The effectiveness of Facebook groups on teaching and improving writing: Students' perceptions," Int. J. Educ. Inf. Technol., vol. 6, no. 1, pp. 87-96, 2012.

[9] M. Yunus et al., "Using Facebook groups in teaching ESL writing," Recent Res. Chem. Biol. Enviroment Cult., pp. 75-80, 2011.

[10] M. M. Yunus, H. Salehi, and C. Chenzi, "Integrating social networking tools into ESL writing classroom: Strengths and weaknesses," English Lang. Teach., vol. 5, no. 8, pp. 42-48, 2012.

[11] M. Kuteeva, "Wikis and academic writing: Changing the writer-reader relationship," English Specif. Purp., vol. 30, no. 1, pp. 44-57, 2011.

[12] M. Schraudner, "The Online Teacher 's Assistant: Using Automated Correction Programs to Supplement Learning and Lesson Planning," pp. 124-136.

[13] N. Abdul Razak, M. Saeed, and Z. Ahmad, "Adopting social networking sites (SNSs) as interactive communities among English foreign language (EFL) learners in writing: Opportunities and challenges," English Lang. Teach., vol. 6, no. 11, pp. 187-198, 2013.

[14] A. Abu Naba'h, J. Hussain, A. Al-omari, and S. Shdeifat, "The Effect of Computer Assisted Language Learning in Teaching English Grammar on the Achievement of Secondary Students in Jordan," Int. Arab J. Inf. Technol., vol. 6, no. 4, pp. 431-439, 2009.

[15] G. Barani, "The relationship between Computer Assisted Language Learning (CALL) and listening skill of iranian EFL learners," Procedia - Soc. Behav. Sci., vol. 15, pp. 4059-4063, 2011.

[16] C. A. (Iowa S. U. Chappelle, "Computer Applications in Second Language Acquisition: Foundations for teaching, testing and research," Comput. Assist. Lang. Learn., vol. 23, no. 1, pp. 229-245, 2004.

[17] A. I. Fageeh, "EFL learners' use of blogging for developing writing skills and enhancing attitudes towards English learning: An exploratory study," J. Lang. Lit., vol. 2, no. 1, pp. 31-48, 2011.

[18] J. Bloch, "From the special issue editor," Lang. Learn. Technol., vol. 12, no. 2, pp. 2-6, 2008.

[19] M. Ware, P., and Warschauer, Electronic feedback and second language writing. Cambridge: Cambridge University Press, 2006.

[20] S. Wichadee, "Peer feedback on facebook: The use of social networking websites to develop writing ability of undergraduate students," Turkish Online J. Distance Educ., vol. 14, no. 4, pp. 260-270, 2013.

[21] F. Van Beuningen, C. G., De Jong, N. H., \& Kuken, "Evidence on the effectiveness of comprehensive error correction in second language writing," Lang. Learn., vol. 62, no. 
1, pp. 1-41, 2012.

[22] D. Bitchener, J., Young, S., \& Cameron, "The effect of different typess of corrective feedback on ESL student writing," J. Second Lang. Writ., vol. 14, pp. 191-205, 2005.

[23] S. Firth, "Developing self-correcting and self-monitoring strategies," TESL Talk, vol. 17, no. 1 , pp. 148-152, 1987.

[24] M. Tocalli-Beller, A. \& Swain, "Reformulation: The cognitive conflict and L2 learning it generates," Int. J. Appl. Linguist., vol. 15, pp. 5-28, 2005.

[25] S. Prvinchandar and A. F. M. Ayub, "Comparison of the effectiveness of styleWriter and microsoft word computer software to improve english writing skills," English Lang. Teach., vol. 7, no. 1, pp. 93-102, 2014.

[26] M. Ghandi, M. \& Maghsoudi, "The effects of direct and indirect corrective feedback on Iranian EFL learners' spelling errors," English Lang. Teach., vol. 7, no. 8, pp. 53-60, 2014.

[27] S. Ahmadi-Azad, "The effect of coded and uncoded written corrective feedback types on Iranian EFL learners' writing accuracy," Theory Pract. Lang. Stud., vol. 4, no. 5, pp. 1001-1008, 2014.

[28] G. Storch, N., \& Wigglesworth, "Learners' processing, uptake, and retention of corrective feedback on writing," Stud. Second Lang. Acquis., vol. 32, pp. 303-334, 2010.

[29] E. Maleki, A. \& Eslami, "The effects of written corrective feedback techniques on EFL students' control over grammatical construction of their written English," Theory Pract. Lang. Stud., vol. 3, no. 7, pp. 1250-1257, 2013.

[30] R. K. Yin, Case study research: Design and Methods, 3rd ed. Thousand Oaks, CA: Sage Publications, 2003.

[31] M. Q. Patton, Qualitative research and evaluation methods, 3rd ed. Thousand Oaks, CA: Sage Publications, 2002.

[32] J. W. Creswell, Educational research: Planning, conducting and evaluating quantitative and qualitative research, 4th ed. Boston: Pearson Education Inc., 2012.

[33] K. Hyland and F. Hyland, "Feedback on second language students' writing," Lang. Teach., vol. 39, no. 02, p. 83, 2006.

[34] Z. K. Saadi and M. Saadat, "EFL Learners' Writing Accuracy: Effects of Direct and Metalinguistic Electronic Feedback," Theory Pract. Lang. Stud., vol. 5, no. 10, pp. 2053 2063, 2015. 